\title{
Cine y Filosofía
}

\author{
Julio Cabrera*
}

Universidad de Brasilia

Filósofo argentino radicado en Brasil, Julio Cabrera se ocupa de filosofía del lenguaje y argumentación, filosofía del cine y filosofar desde América Latina. Autor de alrededor 20 libros, entre los cuales se destacan "Crítica de la Moral Afirmativa" (Barcelona, 2014, 2a edición), "Cine: 100 años de Filosofía” (Barcelona, 2015, 2 edición), "Análisis y existencia" (Argentina, 2010) e "Introduction to a negative approach to argumentation" (Inglaterra, 2019), además de numerosos artículos publicados en América Latina (Venezuela, Chile, Colombia, Argentina, Brasil, México) y Europa (Italia, Francia, Alemania, Portugal, España). Debemos al autor este reordenamiento de su obra sobre cine, a la vez que remitimos a su blog para una imprescindible ampliación de información: filosofojuliocabrera.blogspot.com

\section{Artículos y libros sobre Cine y Filosofía}

Los siguientes textos sobre cine se ubican dentro de una filosofía del lenguaje pluralista (que considera al cine como un lenguaje interactivo y refractivo) y dentro de una reflexión meta-filosófica (que ve al cine como una forma de generación de conceptos). La mejor obra para entender estas interfaces es "Margens das filosofías da linguagem" (Brasilia, 2009, $1^{a}$ reedición) (Existe traducción española inédita de esta obra: Introducción a las filosofías del lenguaje, 2020).

\section{Artículos publicados}

(1) Hitchcock entre Zizek y Aristóteles. Revista Signos, Universidad Autónoma Metropolitana, México, 2002. (Página web de Julio Cabrera).

(2) El carácter trans-estético de los conceptos-imagen. Revista La Ventana Indiscreta, La Plata, Argentina, año 2, número 5, 2007.

(3) La irreconocible negatividad de lo humano. (El talentoso Ripley, Hitler y el Elefante). La Ventana Indiscreta, año 2, número 6, La Plata, 2008.

(4) El otro lado de la ciudad prohibida. La Ventana Indiscreta, año 3, número 8, La Plata, 2008.

(5) Recordando sem ira (em: Sylvio Back (Org). A guerra dos pelados. Annablume, São Paulo, 2008).

(6) Para una des-comprensión filosófica del cine: el caso Inland Empire de David Lynch. Revista Enlaces, Venezuela, 2009: https://dialnet.unirioja.es/servlet/articulo?codigo $=3003168$

(7) Eutanasia poética. Reflexiones sobre cine y filosofía. En: Ética y Cine Journal, Buenos Aires, 2013: https://journal.eticaycine.org/Eutanasia-poetica-Reflexiones-sobre-cine-y-filosofia

(8) Existencia naufragada: los 4 viajes del Titanic. Revista Per la Filosofia, Italia, 2015: https://www.torrossa.com/en/ resources/an/3069784

(9) Repetición y cine vacío. En: La imagen primigenia, La cueva de Chauvet, Buenos Aires, 2016 
(10) Cine, filosofía y filosofía analítica. En: Cine y Pensamiento. Santamaria Freddy (ed), Medellín, Colombia, 2017: http://digital.casalini.it/10.1400/234546

(11) El tema de la repetición en el cine: un desafío filosófico. En La Cueva de Chauvet. https://lacuevadechauvet.com/ el-tema-de-la-repeticion-en-el-cine-un-desafio-filosofico/

Observación: Los artículos fundamentales son (6) y (9).

\section{Textos inéditos}

1. Discussão com Rodrigo Cássio Oliveira: cinema e filosofia. Da logopatia à linguagem cinematográfica.

2. Cine y Filosofía (Entrevista respondida en el Portal-educ.ar, de la Argentina).

3. Restos de un libro ido. (Escritos sobre cine y filosofía)

Estos textos pueden ser encontrados en la página web filosofojuliocabrera.blogspot.com

\section{Libros publicados}

(a) Cine: 100 años de Filosofía (1999, segunda edición corregida, aumentada e ilustrada, de 2015). Gedisa, Barcelona. (Hay traducción italiana de este libro: Da Aristotele a Spielberg. Mondadori, 2000, y traducción portuguesa: O Cinema Pensa. Rocco, Rio de Janeiro, 2006).

(b) De Hitchcock a Greenaway pela história da filosofia. Ed. Nankin, São Paulo, 2007: https://repositorio.unb.br/ handle/10482/15246(ESTE LINK ES DE ACCESO ABIERTO) y https://www.amazon.com/Hitchcock-Greenaway-Pela-Hist\%C3\%B3ria-Filosofia/dp/8577510026 (LINK DE AMAZON PARA ADQUIRIR EL LIBRO)

(c) Diálogo/Cinema. Ed. Senac, São Paulo, 2013, em co-autoria com Márcia Tiburi: https://www.amazon.com/-/es/ Marcia-Tiburi-ebook/dp/B074G17KC8 (LINK DE AMAZON PARA ADQUIRIR EL LIBRO)

Observación: El libro fundamental es (a) en la segunda edición, de 2015. Y también el capítulo I del libro (b), “De regreso a la teoría, siete años después: reconsideración de los conceptos-imagen” (en portugués). 